\title{
Natural $\beta$-chitin-protein complex film obtained from waste razor shells for transdermal capsaicin carrier
}

\author{
Volkan Aylanc a, Seymanur Ertosun ${ }^{\text {a }}$, Lalehan Akyuz ${ }^{\text {b }}$, Behlul Koc Bilican ${ }^{\text {c }}$, Semih Gokdag ${ }^{\text {c }}$, Ismail Bilican ${ }^{\text {d }}$, \\ Yavuz Selim Cakmak ${ }^{\mathrm{c}}$, Bahar Akyuz Yilmaz ${ }^{\mathrm{c}}$, Murat Kaya ${ }^{\mathrm{c}, *}$ \\ a Centro de Investigação de Montanha (CIMO), Instituto Politécnico de Bragança, Campus de Santa Apolónia, 5300-253 Bragança, Portugal \\ ${ }^{\mathrm{b}}$ Aksaray University, Technical Vocational School, Department of Chemistry Technology, 68100 Aksaray, Turkey \\ c Department of Biotechnology and Molecular Biology, Faculty of Science and Letters, Aksaray University, 68100 Aksaray, Turkey \\ d Science and Technology Application and Research Center, Aksaray University, Aksaray 68100, Turkey
}

\section{A R T I C L E I N F O}

\section{Article history:}

Received 5 January 2020

Received in revised form 25 March 2020

Accepted 26 March 2020

Available online 30 March 2020

\section{Keywords:}

B-chitin

Biodegradable film

Bio-waste

Transdermal patch

Capsaicin

\begin{abstract}
A B S T R A C T
In the literature, the produced $\beta$-chitin samples are in powder or flake forms but there is no natural $\beta$-chitin based film. Also, the commercially available transdermal patches are produced from synthetic polymers. In this regard, we produced natural $\beta$-chitin-protein complex (CPC) film from the waste shells of Ensis spp. The obtained natural film was characterized by FTIR, TGA and SEM. Additionally, swelling, thickness, contact angle and antioxidant tests were done to learn more about the films. After production and characterization of the film, capsaicin, which is commonly used for pain relief was loaded into the film. The loading capacity was recorded as $5.79 \%$. The kinetic models were studied in three different $\mathrm{pH}$, then the results were fitted with Higuchi model with high correlation at $\mathrm{pH}$ 7.4. After considering all the obtained results, the capsaicin loaded CPC film may be an alternative candidate for transdermal patch instead of the synthetic ones.
\end{abstract}

(c) 2020 Elsevier B.V. All rights reserved.

\section{Introduction}

Transdermal patches are various pharmaceutical materials comprising active drug substance, preferred for rapid release, protecting skin or wound from microorganisms, absorbing body secretions, cost-effective synthetic based polymers [1,2]. However, considering the adverse effects of these synthetic materials on human health, their use is limited compared to natural polymers. For this purpose, the focus has been on the development of functional bio-based patches, which are more successful in clinical results than synthetic patches due to their faster healing, microbial control, minimizing toxicity or side effects $[1,3]$. In addition, biological patches are biodegradable and biocompatible as well as have strong thermal and mechanical properties. Previous studies are generally based on synthetically obtained chitosan hydrogels, alginate, poly (lactic-co-glycolic acid) (PLGA) or dextran. However, there has been no study for transdermal drug release by using a natural patch, which is obtained directly from the organism by keeping its natural three-dimensional structure.

Natural polymers, especially chitin-based biological films, have attracted greater attention than other films because of their applicability to foods and drugs, and also thanks to their biodegradable [4], non-toxic

\footnotetext{
* Corresponding author at: Aksaray University, Faculty of Science and Letters, Department of Biotechnology and Molecular Biology, 68100 Aksaray, Turkey.

E-mail address: muratkaya@aksaray.edu.tr (M. Kaya).
}

[5], antimicrobial [6] and biocompatible features [7]. In the literature, there are also composite film studies made by adding chitin to synthetic polymers such as $\mathrm{N}$ - lithium chloride/ $\mathrm{N}$ dimethylacetamide ( $\mathrm{LiCl} /$ DMAc) [8,9]. However, this situation does not eliminate toxic effects, but increases the cost and also causes chitin films to lose some of their functions, so it limits the use of the films [10]. Because of these limitations, chitin based films obtained by preserving the natural structure of organisms and avoiding chemicals have gained importance in recent years [10].

Converting bio-waste from marine organisms into value added materials has been one of the most interesting subjects of recent times. In this context, a potential organism for evaluation is razor shell (Ensis spp.), a member of the aquatic ecosystem (Bivalvea, Mollusca) characterized by long and fragile shells. So far, 22 species have been identified in this group. The geographical distribution of Ensis species extends from the European coast and the tropical region of West Africa to the Asian and American coasts [11-13]. Ensis species has an economic value used both as food [14] and feed in fishing and shrimp cultures [15]. As a result of this use, different studies have been carried out on the waste razor shells. For example, razor clam shells were used as calcium oxide $(\mathrm{CaO})$ source for transesterification in biodiesel production [16], nano-bioceramic material to replace artificial bone [17], removal of heavy metals and dyes from industrial waste water $[18,19]$. In the literature, chitin has been defined in some species of Bivalvia (oyster, clam, etc.) and there is no chitin study for Ensis species belonging to 
this class. Studies on Ensis species were limited to taxonomy [12], molecular identification [20], morphology [21], cytogenetics [22], anatomy [23], mechanical [24] and elasticity properties [25]. In the present study, razor shells was selected as CPC film source because of the following reasons; i) high survival rate, ii) easy cultivation, iii) worldwide distribution and iv) becomes completely bio-waste after consumption as food/feed.

Capsaicin (trans-8-methyl-N-vanilyl-6-nonenamide) is an alkaloid in the group of capsaicinoids and it has various pharmacological effects such as anti-inflammatory [26], anti-obesity [27], antioxidant [28] and antibacterial [29]. In addition, due to its strong analgesic effect, it is frequently used as a painkiller [30]. Capsaicin is readily soluble in methanol, ethanol, alkali aqueous solutions and chloroform, but is almost insoluble in water. Capsaicin has limited clinical use due to its short half-life (about $2 \mathrm{~h}$ ), strong temperature and burning sensation. However, in some clinical studies, low doses of capsaicin have been shown to have moderate efficacy in the treatment of musculoskeletal and peripheral neuropathic pain syndrome [31,32]. In another clinical study, it was found that capsaicin patches (5-10\%) used to prevent pain after postherpetic neuralgia herpes zosterin treatment significantly reduced pain in 2-12 weeks [33].

In this study, for the first time, natural CPC film was obtained by preserving the natural three-dimensional structure of the razor shells. Then, physicochemical features were determined by swelling properties, contact angle, film thickness, FT-IR, TGA and SEM analyzes. The antioxidant activity of capsaicin loaded film was also evaluated. After that capsaicin was loaded into CPC film and releasing properties were reported.

\section{Material and methods}

\subsection{Sample collection and materials}

Waste shells of individuals belonging to Ensis species were collected from a local fisher in July 2019 in Izmir, Turkey. Shell samples (24 individuals) were washed repeatedly with distilled water to remove the dust and particles and then dried at room temperature for one week. During the experiment, chemicals used for film isolation; $\mathrm{HCl}$ and $\mathrm{NaOH}$ were obtained from Merck and Capsaicin (CAS Number: 40486-4) was purchased from Sigma Aldrich. The chemicals used in capsaicin loading and release studies (methanol, chloroform and acetic acid) were purchased from Sigma Aldrich, and $\mathrm{NaCH}_{3} \mathrm{COO}, \mathrm{Na}_{2} \mathrm{HPO}_{4}{ }^{*} 12 \mathrm{H}_{2} \mathrm{O}$, $\mathrm{NaH}_{2} \mathrm{PO}_{4}{ }^{*} 2 \mathrm{H}_{2} \mathrm{O}$ and $\mathrm{NaCl}$ from Merck. DPPH (2,2-diphenyl-1picrilhydrazil) (CAS Number: 1898-66-4) used for the antioxidant study was purchased from Sigma-Aldrich. Distilled water was used in all the experiments.

\subsection{Method for chitin film isolation}

In order to produce natural CPC film from the shells of the Ensis spp., minerals and proteins from the structure of the shells were removed using a reported method from our previous study with some modifications [34]. First, the samples were treated with $1 \mathrm{M}$ $\mathrm{HCl}$ solution for demineralization at room temperature for $2 \mathrm{~h}$. The samples were then washed with distilled water until reaching neutral $\mathrm{pH}$. The demineralized samples were then treated with $1 \mathrm{M} \mathrm{NaOH}$ solution for deproteinization at $40{ }^{\circ} \mathrm{C}$ for $5 \mathrm{~h}$. Deproteinization was carried out using a low molar $\mathrm{NaOH}$ solution to maintain the three-dimensional structure of natural films without stirring and boiling under extremely gentle conditions. Ensis spp. samples were then washed with distilled water until reaching neutral $\mathrm{pH}$. Finally, the obtained films were dried at room temperature for two days.

\subsection{Characterization of natural CPC film}

\subsubsection{Appearance and thickness of natural CPC films}

The images of the obtained natural CPC films were examined by light microscope (Leica Z6 APO). The thickness of the films were measured by digital micrometer (Mitutoyo). The average of the measurements taken from different parts of the films was used to determine the thickness of the natural film.

\subsubsection{Fourier transform infrared spectroscopy (FT-IR)}

FT-IR analysis was performed to determine the structure of the CPC film. Also FT-IR results were used to show capsaicin loading into the film. The absorption bands were recorded over the frequency range of $4000-600 \mathrm{~cm}^{-1}$ with Perkin-Elmer FT-IR spectrometer at the resolution of $4 \mathrm{~cm}^{-1}$.

\subsubsection{Scanning Electron Microscopy (SEM)}

The surface morphology of the films were examined using SEM with $5 \mathrm{kV}$ and magnification from 10,000-40,000×. Film samples were coated with gold / palladium by Sputter Coater (Cressingto Auto 108) and then recorded with the FEI Quanta FEG 250 SEM instrument.

\subsubsection{Thermogravimetric analysis (TGA)}

The thermal stability of the CPC film sample was analyzed using the EXSTAR S1 7300 Thermogravimetric Analyzer. The sample was heated from $30{ }^{\circ} \mathrm{C}$ to $650{ }^{\circ} \mathrm{C}$ at a heating rate of $10{ }^{\circ} \mathrm{C} \mathrm{min}{ }^{-1}$ under nitrogen atmosphere.

\subsubsection{Water contact angle measurements}

The water contact angles of the films were determined using the Data Physics video-based contact angle measurement system (contact angle OCA30). Following the Owens, Wendt, Rabel ve Kaelble (OWRK) Method, the mean of ten different measurements was obtained to measure the hydrophobicity of the film samples.

\subsubsection{Swelling test}

The swelling ratio of the natural CPC film was measured using the weighing method. The previously dried film samples were cut to a size of $1 \mathrm{~cm} \times 1 \mathrm{~cm}$ and dry weights were taken. After taking $20 \mathrm{~mL}$ of each buffer solution ( $\mathrm{pH} 4.0$, pH 5.5 and pH 7.4), weighed film samples were added. The film samples were separately stored for $3 \mathrm{~h}$ and $24 \mathrm{~h}$ at $25^{\circ} \mathrm{C}$ and $37^{\circ} \mathrm{C}$ in the buffer solutions. Finally, the film samples were removed from buffer solution carefully and the surface waters were removed with filter paper and then the films were weighed. Swelling ratio was calculated using the following equation;

$S R(\%)=\frac{W_{s}-W_{d}}{W_{d}} \times 100$

$S R$; swelling ratio, $W_{d}(\mathrm{~g})$; the dry weight of the film and $W_{s}(\mathrm{~g})$; the weight of the film swollen in buffer solution.

\subsection{Method for capsaicin loading}

\subsubsection{Capsaicin loading}

The passive loading technique used in a previous study was modified and used to load capsaicin into the natural CPC film [35]. In this technique, $100 \mathrm{mg}$ of capsaicin was dissolved in $8 \mathrm{~mL}$ of methanol for $10 \mathrm{~min}$ using a sonicator. After adding $200 \mathrm{mg}$ of natural CPC film to this solution, it was vortexed for $10 \mathrm{~min}$ and then was incubated at $120 \mathrm{rpm}$ in a shaker at room temperature for $48 \mathrm{~h}$. The samples were then filtered with filter paper having a pore size of $110 \mu \mathrm{m}$. Capsaicin loaded films were dried for $24 \mathrm{~h}$ at $50{ }^{\circ} \mathrm{C}$. 


\subsubsection{Capsaicin loading efficiency}

The quantitative determination of capsaicin loaded on natural CPC film was performed by modification of a previously reported method [36]. The concentrations of different standards; $5 \mu \mathrm{g} / \mathrm{mL}, 10 \mu \mathrm{g} / \mathrm{mL}$, $15 \mu \mathrm{g} / \mathrm{mL}, 20 \mu \mathrm{g} / \mathrm{mL}$ and $25 \mu \mathrm{g} / \mathrm{mL}$ were prepared to obtain the calibration curve. The absorbance of these solutions was measured at $280 \mathrm{~nm}$ for capsaicin using UV-vis spectrophotometer. In the loading efficiency studies, $2 \mathrm{~mL}$ of chloroform was added to the natural CPC film loaded with $10 \mathrm{mg}$ of capsaicin and vortexed for $10 \mathrm{~min}$. The samples were then centrifuged for $5 \mathrm{~min}$ at $9000 \mathrm{rpm}$. The clear solution was taken and measured using UV-vis spectrophotometer at $280 \mathrm{~nm}$ wavelength and the amount of capsaicin loaded was calculated. The following equation is used to calculate the loading efficiency;

\section{Capsaicin loading efficiency (\%)}

$$
=\frac{\text { Calculated capsaicin loading }}{\text { Theoretical capsaicin loading }} \times 100
$$

\subsection{Method for capsaicin release}

In vitro release studies of capsaicin loaded natural CPC films by passive loading technique were performed at acetate buffer ( $\mathrm{pH} 4)$ and phosphate buffer ( $\mathrm{pH} 5.5$ and $\mathrm{pH} 7.4$ ). Since the physiological pH is accepted as 7.4 and the skin $\mathrm{pH}$ is accepted as $4.0-7.0$, these $\mathrm{pH}$ values are preferred [37]. In vitro, capsaicin release studies were performed using the dialysis method which is the most commonly reported method in the literature for release studies [38], encapsulation and controlled release of bioactive compounds in lactoferrin-glycomacropeptide nanohydrogels: curcumin and caffeine as model compounds, chitosan/ fucoidan $[39,40]$. Five $\mathrm{mg}$ of CPC films containing capsaicin in dialysis bags were added to $5 \mathrm{~mL}$ of $\mathrm{pH} 4.0$ buffer. The samples were then placed in $50 \mathrm{~mL}$ of their own buffer solution ( $\mathrm{pH} 4.0)$ in the dialysis bag for the diffusion of capsaicin into the outer media and simulation of the in vivo environment [38]. It was stirred in a water bath at $37^{\circ} \mathrm{C}$ at $120 \mathrm{rpm}$ for $120 \mathrm{~h}$. Then, to calculate the amounts of capsaicin released from the natural CPC films loaded with capsaicin in the dialysis bag, $2 \mathrm{~mL}$ of $\mathrm{pH} 4.0$ buffer was withdrawn at different time intervals $(5 \mathrm{~min}, 15 \mathrm{~min}$, 30 min, 1 h, 2 h, 4 h, 6 h, 12 h, 24 h, 48 h, 72 h, 96 h and 120 h) and the same amount of fresh $\mathrm{pH} 4.0$ buffer solution was added to the medium. The amount of capsaicin released into the medium was measured using UV-vis spectrophotometer at $280 \mathrm{~nm}$. In addition, $5 \mathrm{mg}$ of pure capsaicin was added to $\mathrm{pH} 4.0$ buffer solution as a control group and the same procedures were performed. Additionally, the same procedures for pure capsaicin and CPC film were performed for $\mathrm{pH} 5.5$ and $\mathrm{pH} 7.4$ buffers. The following equations are used to calculate the cumulative percent release of capsaicin;

Amount of Capsaicin (mg)

$=($ Concentration $\times$ Dissolution bath volume $)$

Cumulative release $(\%)=\frac{\text { Sample taken volume }(m L)}{\text { Bath volume }(m L)} \times P(t-1)+P t$

$P t$ is the rate of free release at time t, and $P(t-1)$ is the rate of free release before $t$.

\subsection{Capsaicin release kinetics}

Numerous mathematical models are widely used for in vitro release studies of loaded drugs. These models are; zero order, first order, Higuchi, Hixson-Crowell, Korsmeyer-Peppas, Baker-Lonsdale, Weibull, Hopfenberg, Gompertz and regression models [41].

In this study, zero order, first order and Higuchi kinetic models were used to compare capsaicin release kinetics of natural CPC film. Zeroorder model is preferred to determine release in transdermal systems, first-order model in porous matrices, and Higuchi kinetic model dissolution of drugs in some transdermal systems and matrices.

The zero order kinetic model was calculated by the following equation;

$Q_{t}=Q_{0}+k_{0} t$

$Q_{t}$ is the amount of cumulative capsaicin released at time t, $Q_{0}$ is the initial amount of capsaicin in the matrix, $k_{0}$ is constant with zero release and $t$ is time. In order to determine the release kinetics of capsaicin, the cumulative value of the released capsaicin was determined by plotting the quantity-time graph.

The first order kinetic model is expressed by the equation given below [42];

$\log Q_{t}=\log Q_{0}+k_{1} t / 2.303$

$Q_{t}$ is the cumulative amount of capsaicin released at time $t, Q_{0}$ is the initial amount of capsaicin in solution, $k_{1}$ is the first-order release constant, $t$ is time and $k_{1} / 2.303$ is the slope of the line. In order to explain the release kinetics of capsaicin released from natural CPC films, the daily cumulative percentage value of capsaicin - time is indicated by plotting.

The Higuchi kinetic model is based on the Fickian diffusion mechanism and is expressed by the simplified square root of the time equation [43].

$Q_{t}=Q_{0}+k_{H} t^{1 / 2}$

$k_{H}$ is the Higuchi constant and $t$ is the time. In order to explain the release kinetics of capsaicin, the cumulative amount of drug released square root of time is plotted.

\subsection{Antioxidant activity}

DPPH radical scavenging activity of the control and capsaicin-loaded natural CPC films were determined by modification of the method previously reported by Bersuder et al. [44]. First, the film samples were divided into small pieces $(10 \mathrm{mg}$ ) and placed in test tubes. Then $1.0 \mathrm{~mL}$ of DPPH solution prepared at a concentration of $6 \times 10^{-5} \mathrm{M}$ was added to each film sample and incubated for $10 \mathrm{~min}$ in dark at room temperature. At the end of incubation, samples were measured using UV-vis spectrophotometer at $517 \mathrm{~nm}$ wavelength. The test was carried out in triplicate and the DPPH radical scavenging activity was calculated using the following equation;

Inhibition $(I \%)=\left(\frac{A_{\text {control }}-A_{\text {sample }}}{A_{\text {control }}}\right) \times 100$

$A_{\text {control }}$ is the absorbance of DPPH while $A_{\text {sample }}$ is the absorbance of $\mathrm{CPC}$ film + DPPH.

\section{Results and discussion}

\subsection{Thickness}

The thickness of the CPC film is an important parameter in order to determining the physical properties and application area of the film. In this study, it is shown that homogeneous natural CPC films have preserved the three-dimensional structure, which derived directly from the organism and has visually transparent structure relatively (Fig. 1). The average of the measurements taken with micrometer from 10 different regions of the natural CPC film which obtained in three dimensions was recorded as $26.9 \pm 3.1 \mu \mathrm{m}$. It is observed that natural CPC film has a finer structure in comparison to synthetically obtained chitosan films in earlier studies [45-48]. 
A

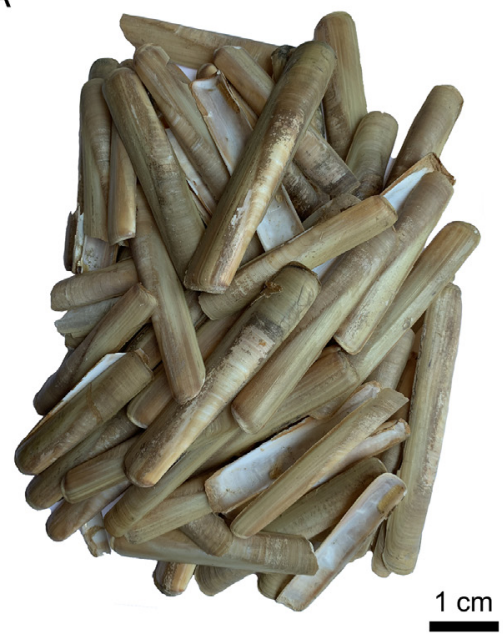

B

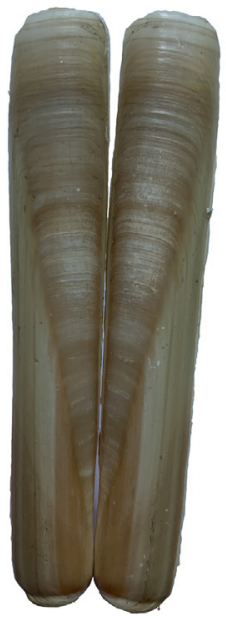

C

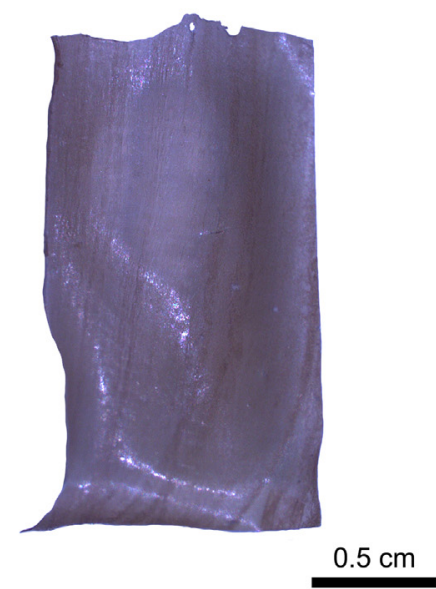

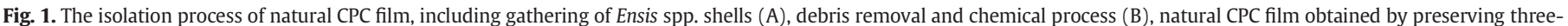
dimensional structure $(\mathrm{C})$.

\subsection{FT-IR}

In order to determine the loading of capsaicin into the natural CPC film, FT-IR analysis was carried out via comparison of the specific peaks of the capsaicin, CPC film and capsaicin loaded CPC film. The spectra of films and pure capsaicin are given in Fig. 2.

The first spectrum is belonging to pure capsaicin. Phenolic $\mathrm{OH}$ bond of capsaicin was observed at the $3310.86 \mathrm{~cm}^{-1}$ as a sharp peak. The $\mathrm{C}-\mathrm{H}$ aliphatic stretching peaks of the chain structure and alkoxy group $\left(\mathrm{O}-\mathrm{CH}_{3}\right)$ were recorded in the range of the 2959.51-2861.38 $\mathrm{cm}^{-1}$. The stretching of the carbonyl group and $\mathrm{N}-\mathrm{H}$ bending of amide group were observed at 1627.25 and $1514.87 \mathrm{~cm}^{-1}$, respectively. $\mathrm{C}-\mathrm{O}$ stretching vibration of methoxy group bonded to the aromatic ring was recorded at $1202.20 \mathrm{~cm}^{-1}$.

Chitin is found in three different forms including $\alpha, \beta$ and $\gamma$. In the FT-IR spectrum, $\beta$-chitin gives a sharp peak at around $1640 \mathrm{~cm}^{-1}$ because of the hydrogen bonds formed between the molecules [49]. According to literature, the amide II band gives a peak at around the $1550 \mathrm{~cm}^{-1}$ [50]. In this study, as seen from the FT-IR spectrum of the isolated natural CPC film, a single and undivided sharp peak was observed at $1631.93 \mathrm{~cm}^{-1}$. However, the amide II band was recorded at lower wavenumber at $1513.71 \mathrm{~cm}^{-1}$. This is because of the intermolecular interactions between chitin and remaining protein. To preserve the film shape of the material, the protein is not completely removed from the structure. The stretching vibration of the functional group $(C=0)$ of the chitin gives a peak at $1632 \mathrm{~cm}^{-1}$ in the pure $\beta$-chitin. However, in the $\mathrm{CPC}$ film spectrum, this $\mathrm{C}=0$ peak was shifted to $1627.25 \mathrm{~cm}^{-1}$ due to the hydrogen bonding between the chitin and protein. In another words, the formation of hydrogen bond shifted the lower wavenumber. In addition, the absence of clear bands at around $1000 \mathrm{~cm}^{-1}$ which is responsible for sugar ring demonstrate the presence of protein in the film structure.

In the natural CPC film, some changes formed at the molecular structure with the loading of the capsaicin due to the intermolecular interactions. After capsaicin loading to CPC film, the observed changes are; i) the intensity of $\mathrm{O}-\mathrm{H}$ band recorded at $3290.44 \mathrm{~cm}^{-1}$ increased due to the new $\mathrm{H}$-bonds, ii) the intensity of $\mathrm{C}-\mathrm{H}$ stretching peaks observed at around 2851.19-2954.06 $\mathrm{cm}^{-1}$ increased with the effect of the aliphatic chain of the capsaicin, iii) amide I and amide II bands of chitin shifted to the different wavenumbers and iv) some of the specific peaks of capsaicin recorded in the range of the $1457.29-1048.73 \mathrm{~cm}^{-1}$ were observed as low intensity. Consequently, the results confirmed that the capsaicin was successfully loaded to natural CPC film.

\subsection{SEM}

The SEM analysis was used to show the surfaces morphology of the newly obtained film and capsaicin loading on its surface. The surface morphology of the CPC film obtained by preserving its natural three-

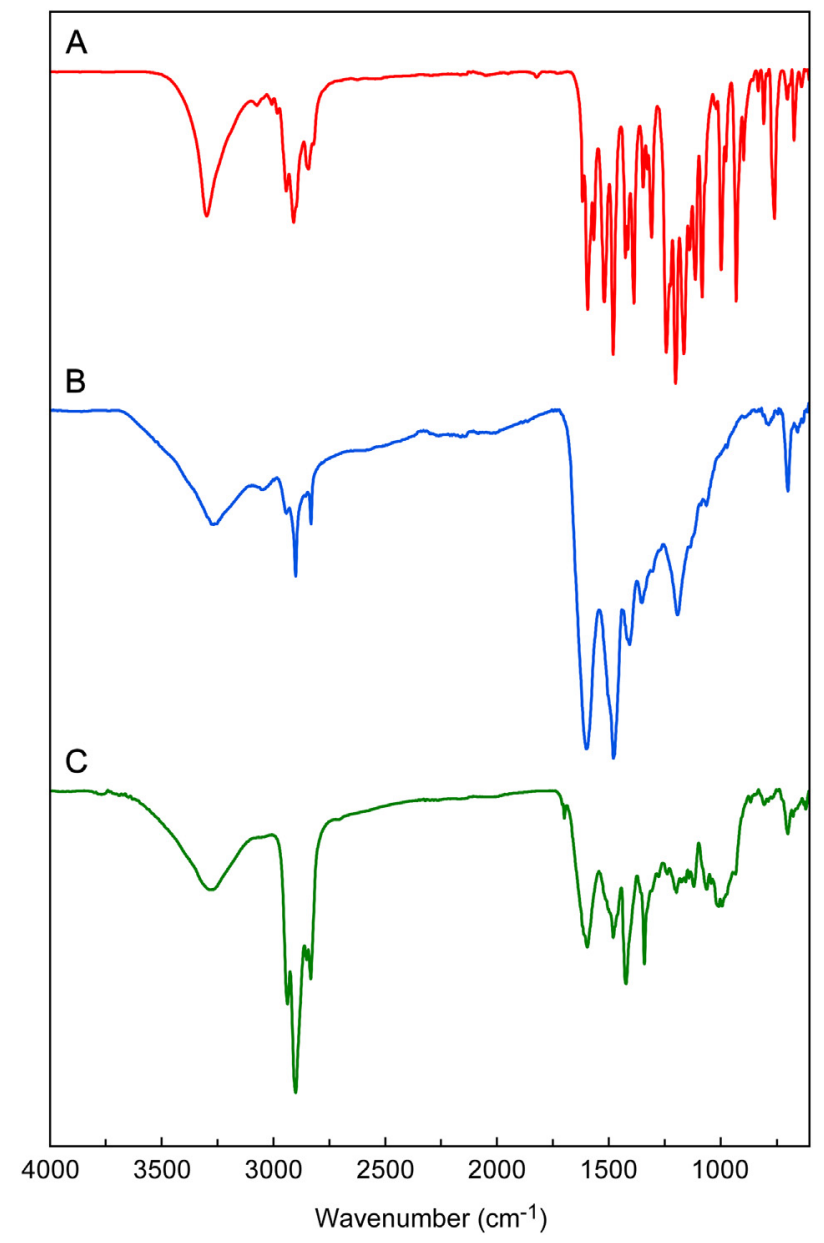

Fig. 2. The FT-IR spectra: pure capsaicin (A), natural CPC film (B), capsaicin loaded natural CPC film (C). 
dimensional structure and the change in surface after capsaicin loading are shown in Fig. 3. Slightly visible and smaller nanofibers observed on the surface of the natural film indicate that the structure is $\beta$-chitin as clarified in previous studies (Fig. 3A) [49]. This result supports the fact that the form of the chitin is $\beta$ with TGA analysis in the current study. In Fig. 3B, it is observed that the nanopores formed between smaller nanofibers are filled with loaded capsaicin. This figure shows that capsaicin was loaded successfully.

\subsection{TGA}

The three-dimensional structure of natural CPC films derived from Ensis spp. was preserved. TGA and DTG thermograms are shown in Fig. 4. Two major mass losses were observed in the TGA curve of the $\mathrm{CPC}$ film. The first of these was recorded at $51.7^{\circ} \mathrm{C}$, which is attributed to the evaporation of trapped water in the film [51]. The second mass loss occurred at $331.6{ }^{\circ} \mathrm{C}$. Previous studies have shown that DTG $\max$ values recorded between 250 and $350{ }^{\circ} \mathrm{C}$ are $\beta$-chitin [5,52,53]. The mass loss at $331.6{ }^{\circ} \mathrm{C}$ can be attributed to the dehydration of chitin saccharide rings and the degradation of acetylated units of the film [54]. In previous studies on the chitin, two mass losses have been similarly reported in the recorded TGA and DTG results [53]. In the present study, it was shown that the thermograms obtained for the natural CPC film showed compatible results with the previous studies and its form was $\beta$-chitin.

\subsection{Contact angle}

The water contact angle is an analysis performed to demonstrate the affinity of the material to water. The result of the analysis is determined by considering the angle formed by a drop of water sent to the surface of the material. In the event this angle rises above $90^{\circ}$, the material is considered hydrophobic. If the angle goes below $90^{\circ}$, the material is considered hydrophilic [55]. The mean water contact angle measurements from 10 different regions of the CPC film were measured as $105.8^{\circ} \pm$ 1.96 , which indicates that the surface of the natural CPC film has a hydrophobic character (Fig. 5). In previous studies, chitin has a relatively high hydrophobicity compared to the films produced synthetically from nanofibrils [46,56], whereas it has similar results with chitin film

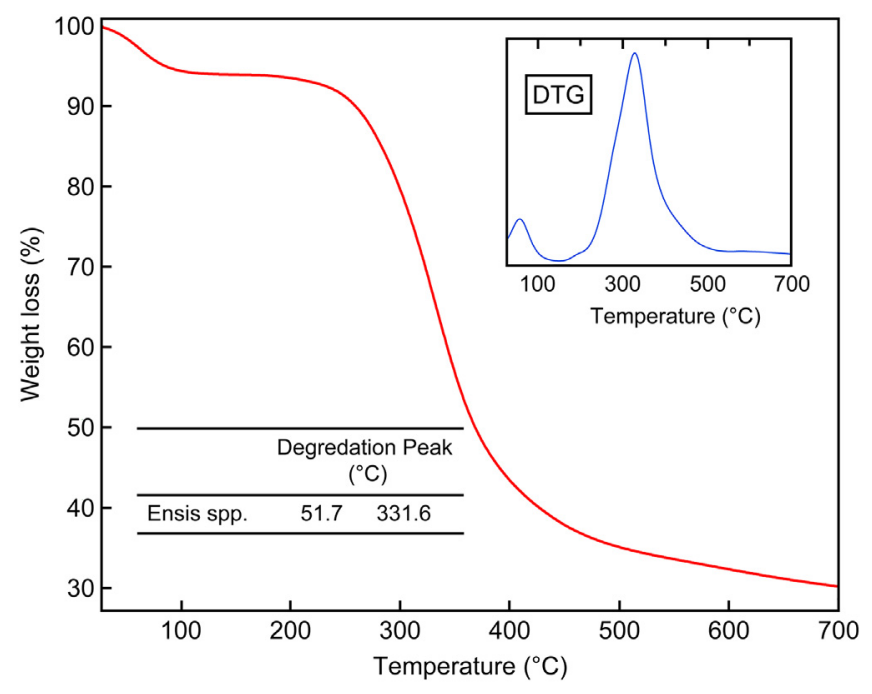

Fig. 4. TGA and DTG thermograms of natural CPC film.

obtained naturally from the cockroach wing in the literature [34]. With this hydrophobic property, the CPC film has potential for use in the medical field. This potential use is further supported by the successful capsaicin carrier study.

\subsection{Natural CPC film swelling test through buffer uptake}

The swelling behavior of films of biological origin is a substantial feature for drug release studies. The swelling properties of natural CPC film at different temperatures and times in PBS and acetate buffer solutions at different $\mathrm{pH}$ values were investigated and the obtained results are given in Table 1. The results showed that the film samples incubated in PBS ( $\mathrm{pH} \mathrm{7.4)}$ at $25{ }^{\circ} \mathrm{C}$ for the swelling test were swollen $20 \%$ in $0-3 \mathrm{~h}$ and $22.24 \%$ in $0-3 \mathrm{~h}$ when incubated at $37^{\circ} \mathrm{C}$. The swelling rate did not change in the incubation medium from 3 to $24 \mathrm{~h}$. Samples incubated in PBS (pH 5.5) were swollen $42.85 \%$ and $27.28 \%$ at $25{ }^{\circ} \mathrm{C}$ and $37^{\circ} \mathrm{C}$ in $0-3 \mathrm{~h}$ period of the time respectively. From 3 to $24 \mathrm{~h}$ no change
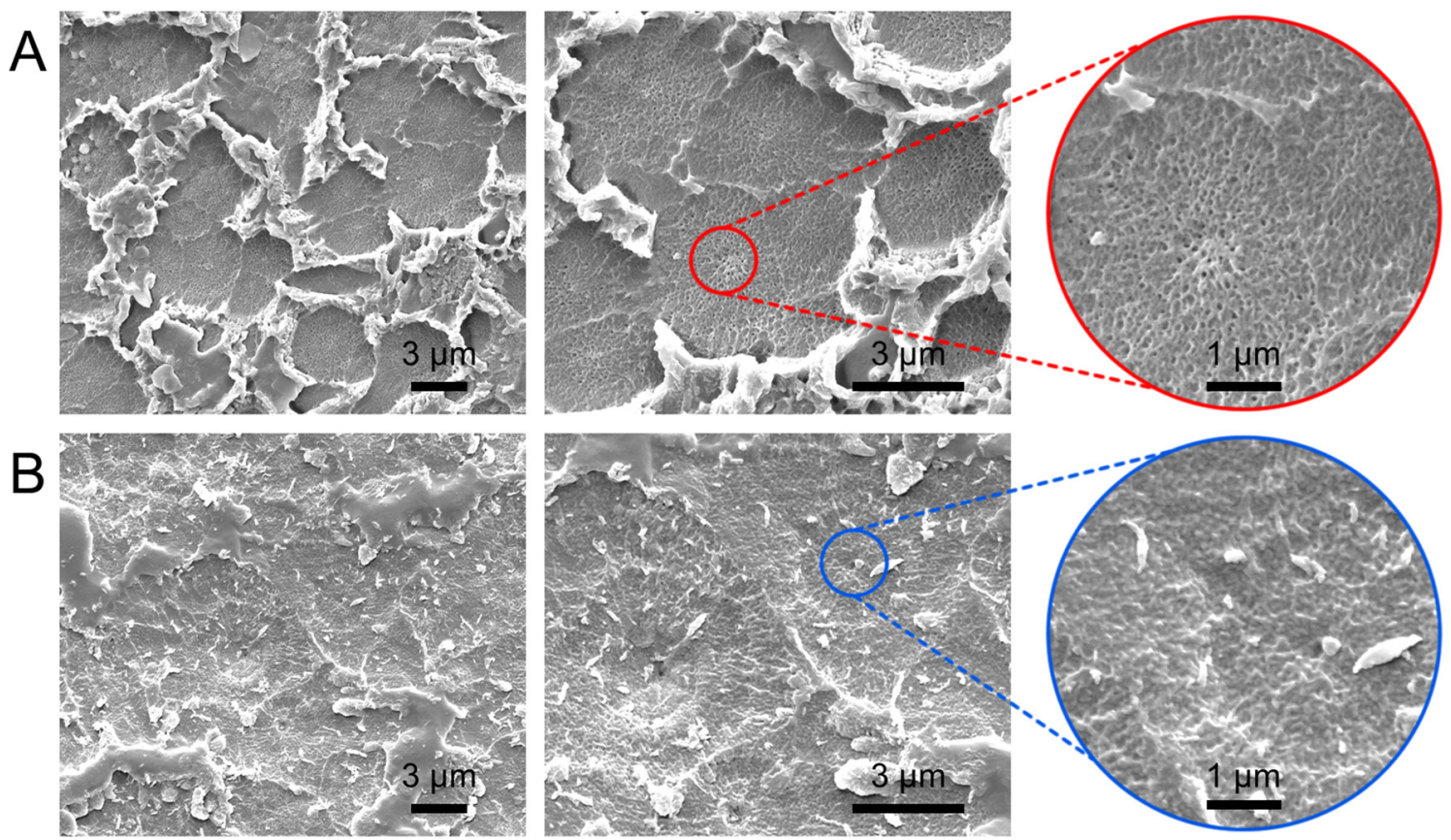

Fig. 3. Scanning electron micrographs (SEM): natural CPC film (A), capsaicin loaded natural CPC film (B). 


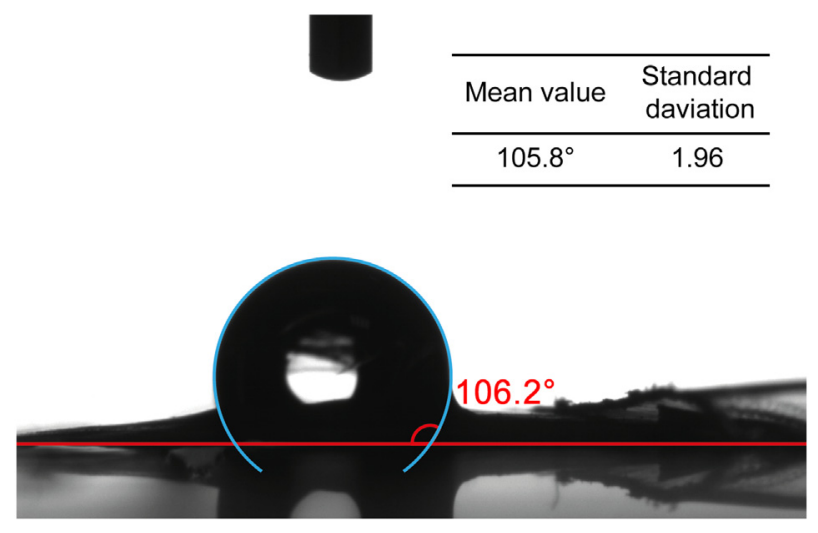

Fig. 5. Contact angle measurement of natural CPC film.

was determined at $25^{\circ} \mathrm{C}$ whereas slight swelling was observed at $37^{\circ} \mathrm{C}$. The film samples in acetate buffer ( $\mathrm{pH} 4.0$ ) swelled to $50 \%$ at both $25^{\circ} \mathrm{C}$ and $37{ }^{\circ} \mathrm{C}$ from 0 to $3 \mathrm{~h}$. Swelling continued slightly from 3 to $24 \mathrm{~h}$ at both temperatures. The highest swelling ratio of the natural CPC film was recorded at $\mathrm{pH} 4.0$ and the acidic medium was found to have a significant effect on the swelling behavior of the film. This can be explained by the fact that $\mathrm{H}$ ions can easily penetrate between $\beta$-chitin layers in acidic medium and disrupt the present interactions in $\beta$-chitin. In the literature, it is explained that the $\beta$-chitin chains do not contain $\mathrm{H}$ bonds that bind these layers together in the layered arrangement [57]. Thus, polar solvents such as water and alcohol allow the $\beta$-chitin to easily enter between the layers and exhibit swelling behavior [57]. The swelling behavior of chitin in different buffer solutions was investigated previously and it was found that aminoethyl chitin tends to swell better in acidic environments rather than in alkaline mediums [58].

Thanks to the high swelling capacity of natural CPC film, it has potential as an alternative natural material for medical applications such as sorption wound dressing.

\subsection{Loading capacity}

The capsaicin loading capacity of the natural CPC film was determined to be $5.79 \%$. The loading capacity of the natural film is not very high. However, when the irritating properties of very low quantities of capsaicin are taken into consideration, this is unlikely to limit the use of natural CPC film as a patch.

\subsection{In vitro capsaicin release}

The release of drugs from carrier systems depends on certain parameters such as $\mathrm{pH}$, surface properties and temperature. In this study, the release properties of capsaicin from natural CPC film were investigated in vitro at $\mathrm{pH} 4.0,5.5$ and 7.4 values. Pure capsaicin (CP) was also used as a control. The release profiles for $\mathrm{CPC}-\mathrm{CP}$ and $\mathrm{CP}$ are given in Fig. 6. Pure capsaicin completely released at all three $\mathrm{pH}$ values. However, in the $\mathrm{CPC}$ film, capsaicin remained stable for $120 \mathrm{~h}$ and the release rate was prolonged. The maximum capsaicin release for $\mathrm{pH} 4.0$, pH 5.5 and pH 7.4 was determined as 50.49\% (48 h), 59.81\% ( $72 \mathrm{~h}$ ) and $59.02 \%$ (96 $\mathrm{h}$ ) respectively.

Table 1

Swelling ratios in buffer solution with different $\mathrm{pH}$ values of natural CPC film (\%).

\begin{tabular}{llllll}
\hline Buffer solution & $0-3 \mathrm{~h}$ & & & $3-24 \mathrm{~h}$ & \\
\cline { 2 - 3 } & $25{ }^{\circ} \mathrm{C}$ & $37{ }^{\circ} \mathrm{C}$ & & $25{ }^{\circ} \mathrm{C}$ & $37{ }^{\circ} \mathrm{C}$ \\
\hline PBS (pH 7.4) & 20.00 & 22.24 & 20.00 & 22.24 \\
PBS (pH 5.5) & 42.85 & 27.28 & & 42.85 & 36.40 \\
Acetate (pH 4.0) & 50.00 & 50.00 & 62.50 & 60.00 \\
\hline
\end{tabular}

There is no $\mathrm{H}$ bond between the $\beta$-chitin polymeric chains and small molecules such as water and alcohol can easily enter between the chains and cause the crystal structure to swell. In addition, the $\mathrm{H}$ bonds in the layers begin to break during the swelling. It has been reported that the swelling property of $\beta$-chitin in water or alcohol is reversible, but it is irreversible in acid solutions where intracellular $\mathrm{H}$ bonds are broken [57,59]. Accordingly, water entering between the $\beta$ chitin film chains both facilitates the diffusion of entrapped capsaicin molecules and burst release as a result of the release of capsaicin, which is retained by weak interactions on the surface. Thus, the release of capsaicin from the carrier system is initially close to pure capsaicin. However, after 6 h, capsaicin release slows down and then a fixed release is observed. The least release rate was found at $\mathrm{pH}$ 4.0. This may be due to the increase in the swelling capacity (Table 1) of the film as the $\mathrm{pH}$ decreases and the binding of capsaicin molecules to the swollen film structure with strong intermolecular bonds such as $\mathrm{H}$ bonds in acidic medium. Consequently, it can be said that the CPC film obtained naturally from razor shell can be used as a drug delivery system.

\subsection{Release kinetics}

The kinetic parameters given in Table 2 were calculated by applying zero-order, first-order and Higuchi models to explain the release mechanism of capsaicin released from the CPC film. The Higuchi model is based on Fickian diffusion and identifies the release kinetics of a drug from an insoluble matrix [60]. When the results of release kinetic studies are examined, it is seen that the correlation coefficient $\left(R^{2}\right)$ of Higuchi model is highest for all $\mathrm{pH}$ values. Thus, the release kinetics of capsaicin from the film are compatible with the Higuchi model.

The release kinetics of transdermal systems are also explained by the Higuchi model [42]. In addition, the drug release kinetics of swelling systems are generally Fickian diffusion-controlled [61]. Capsaicin release kinetics results from CPC film, which is a swelling carrier system found to be in accordance with the literature. The natural CPC film used in this study shows the highest swelling rate at $\mathrm{pH}$ 4.0.

\subsection{Antioxidant}

Antioxidant activities of natural CPC film obtained from Ensis spp. and capsaicin loading on the same film were evaluated by determining DPPH radical scavenging activity. According to the data obtained in the test, the natural CPC film showed $22.09 \%$ inhibition while the radical scavenging activity of capsaicin loaded CPC film increased to $83.43 \%$. Capsaicin is an herbal active secondary metabolite from the alkaloid group with good antioxidant activity [62]. In a previous study, a significant increase was observed in the antioxidant activities of the films obtained by adding capsaicin to the polyurethane film [63]. In another study, the inhibition rate of DPPH increased from $31.72 \%$ in the control group to $94.40 \%$ by adding different amounts of capsaicin to chitosanbased films [64]. According to the data obtained in the present study, free radical removal and antioxidant activity of the CPC film was increased by loading capsaicin in accordance with previous studies.

\section{Conclusion}

In this study, a potential value added product was evaluated from a bio-waste material. Specifically, a natural CPC film was obtained from Ensis spp. bio-waste shells successfully keeping its original shape. The physicochemical properties of the obtained films were determined. Then, capsaicin loading and releasing experiments indicated that this natural CPC film may have biomedical application as a dermal patch after completing in vivo studies. In addition, the produced CPC film could be improved for other bioengineering applications in further studies. 

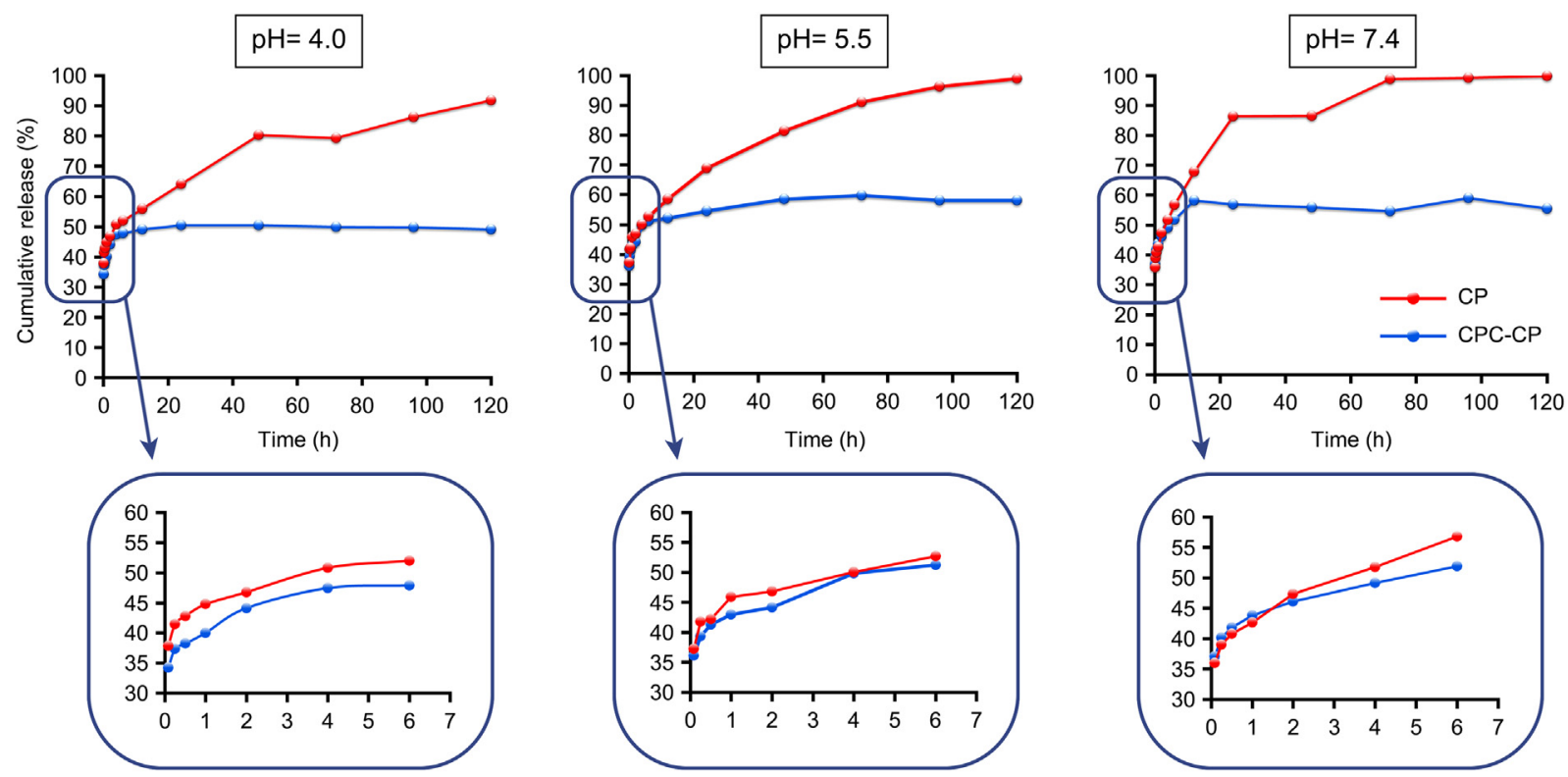

Fig. 6. In vitro capsaicin release profiles for $\mathrm{CPC}-\mathrm{CP}$ and $\mathrm{CP}$ at $\mathrm{pH}=7.4, \mathrm{pH}=5.5$ and $\mathrm{pH}=4.0$.

Table 2

Kinetic parameters of capsaicin loaded natural CPC film.

\begin{tabular}{|c|c|c|c|c|c|c|}
\hline \multirow[t]{2}{*}{ Kinetics models } & \multicolumn{2}{|c|}{ Zero-order } & \multicolumn{2}{|c|}{ First-order } & \multicolumn{2}{|c|}{ Higuchi } \\
\hline & $R^{2}$ & $k_{0}$ & $R^{2}$ & $k_{1}$ & $R^{2}$ & $k_{H}$ \\
\hline $\mathrm{PBS}(\mathrm{pH}=7.4)$ & 0.943 & 0.378 & 0.946 & 0.002 & 0.978 & 3.200 \\
\hline $\operatorname{PBS}(\mathrm{pH}=5.5)$ & 0.671 & 0.303 & 0.670 & 0.002 & 0.715 & 0.026 \\
\hline Acetate $(\mathrm{pH}=4.0)$ & 0.468 & 0.194 & 0.469 & 0.001 & 0.608 & 1.350 \\
\hline
\end{tabular}

\section{Author statement}

Volkan Aylanc: Conceptualization, Formal analysis, Methodology, Investigation, Writing - Original Draft, Writing - Review \& Editing, Visualization

Seymanur Ertosun: Conceptualization, Formal analysis, Methodology, Investigation, Writing - Original Draft

Lalehan Akyuz: Formal analysis, Writing - Review \& Editing, Writing - Original Draft

Behlul Koc Bilican: Investigation, Writing - Original Draft, Writing -

Review \& Editing

Semih Gokdag: Resources

Ismail Bilican: Formal analysis, Writing - Original Draft, Writing - Review \& Editing

Yavuz Selim Cakmak: Formal analysis, Methodology

Bahar Akyuz Yilmaz: Writing - Review \& Editing

Murat Kaya: Supervision, Formal analysis, Resources, Writing - Original Draft, Project administration, Visualization

\section{Acknowledgements}

We would like to thank Timothy Verrinder for proofreading of the manuscript.

\section{References}

[1] K. Kataria, A. Gupta, G. Rath, R. Mathur, S. Dhakate, In vivo wound healing performance of drug loaded electrospun composite nanofibers transdermal patch, Int. J. Pharm. 469 (1) (2014) 102-110.

[2] A.Y. Mensah, P.J. Houghton, R.A. Dickson, T.C. Fleischer, M. Heinrich, P. Bremner, In vitro evaluation of effects of two Ghanaian plants relevant to wound healing, Phytother. Res. 20 (11) (2006) 941-944.

[3] J. Yu, Y. Zhang, A.R. Kahkoska, Z. Gu, Bioresponsive transcutaneous patches, Curr. Opin. Biotech. 48 (2017) 28-32.
[4] S. Nsereko, M. Amiji, Localized delivery of paclitaxel in solid tumors from biodegradable chitin microparticle formulations, Biomaterials 23 (13) (2002) 2723-2731.

[5] Y. Maeda, R. Jayakumar, H. Nagahama, T. Furuike, H. Tamura, Synthesis, characterization and bioactivity studies of novel $\beta$-chitin scaffolds for tissue-engineering applications, Int. J. Biol. Macromol. 42 (5) (2008) 463-467.

[6] A. Dutta, M. Egusa, H. Kaminaka, H. Izawa, M. Morimoto, H. Saimoto, S. Ifuku, Facile preparation of surface $\mathrm{N}$-halamine chitin nanofiber to endow antibacterial and antifungal activities, Carbohydr. Polym. 115 (2015) 342-347.

[7] B. Ding, J. Cai, J. Huang, L. Zhang, Y. Chen, X. Shi, Y. Du, S. Kuga, Facile preparation of robust and biocompatible chitin aerogels, J. Mat. Chem. 22 (12) (2012) 5801-5809.

[8] P.S. Saravana, T.C. Ho, S.-J. Chae, Y.-J. Cho, J.-S. Park, H.-J. Lee, B.-S. Chun, Deep eutectic solvent-based extraction and fabrication of chitin films from crustacean waste, Carbohydr. Polym. 195 (2018) 622-630.

[9] N.L.B.M. Yusof, L.Y. Lim, E. Khor, Flexible chitin films: structural studies, Carbohydr. Res. 339 (16) (2004) 2701-2711.

[10] M. Kaya, A.M. Salaberria, M. Mujtaba, J. Labidi, T. Baran, P. Mulercikas, F. Duman, An inclusive physicochemical comparison of natural and synthetic chitin films, Int. J. Biol. Macromol. 106 (2018) 1062-1070.

[11] S.D. Couñago, J.F. Tajes, Systematics and distribution, Razor clams (2011) 29-44.

[12] F. da Costa, S. Darriba, D. Martínez-Patiño, A. Guerra, Culture possibilities of the razor clam Ensis arcuatus (Pharidae: Bivalvia), Aquac. Res. 42 (10) (2011) 1549-1557.

[13] F. Pernet, N. Malet, A. Pastoureaud, A. Vaquer, C. Quéré, L. Dubroca, Marine diatoms sustain growth of bivalves in a Mediterranean lagoon, J. Sea Res. 68 (2012) 20-32.

[14] H. Saeedi, M.J. Costello, R. von Cosel, First report of anterior pallial tentacles in Solen dactylus (Bivalvia: Solenidae) from the Northern Persian Gulf, Iran, PLoS One 8 (5) (2013).

[15] H. Saeedi, S.P. Raad, A.A. Ardalan, E. Kamrani, B.H. Kiabi, Growth and reproduction of Solen dactylus (Bivalvia: Solenidae) on northern coast of the Persian Gulf (Iran), J. Mar. Biolog. Assoc. U.K. 89 (8) (2009) 1635-1642.

[16] A. Buasri, V. Loryuenyong, The new green catalysts derived from waste razor and surf clam shells for biodiesel production in a continuous reactor, Green Processing and Synthesis 4 (5) (2015) 389-397.

[17] S. Agathopoulos, L. Ozyegin, Z. Ahmad, O. Gunduz, E. Kayali, O. Meydanoglu, F. Oktar, Nano-bioceramics production from razor shell, Key Eng. Mater. 493 (2012) 775-780.

[18] I. Hachoumi, I. El Ouahabi, R. Slimani, B. Cagnon, M. El Haddad, E. Antri, S. Lazar, Adsorption studies with a new biosorbent Ensis siliqua shell powder for removal two textile dyes from aqueous solution, J. Mater. Environ. Sci. 8 (2017) 1448-1459.

[19] I. Hachoumi, V.G. Mihucz, G. Orgován, G. Záray, S. El Antri, S. Lazar, Pod razor (Ensis siliqua) shell powder as cost-effective biomineral for removal of nickel (II), copper (II) and zinc (II) from artificially contaminated industrial wastewater, Sustain. Chem. Pharm. 12 (2019) 100137.

[20] J. Fernández-Tajes, R. Freire, J. Méndez, A simple one-step PCR method for the identification between European and American razor clams species, Food Chem. 118 (4) (2010) 995-998

[21] M.M. Rufino, P. Vasconcelos, F. Pereira, J. Fernández-Tajes, S. Darriba, J. Méndez, M.B. Gaspar, Geographical variation in shell shape of the pod razor shell Ensis siliqua (Bivalvia: Pharidae), Helgol. Mar. Res. 67 (1) (2013) 49-58.

[22] A.M. González-Tizón, V. Rojo, J. Vierna, K.T. Jensen, E. Egea, A. Martínez-Lage, Cytogenetic characterisation of the razor shells Ensis directus (Conrad, 1843) and E. minor (Chenu, 1843)(Mollusca: Bivalvia), Helgol. Mar. Res. 67 (1) (2013) 73.

[23] M. Pyke, Evaluation of Good Handling Practice for Razor Clams, Seafish Report No. SR548, 2002.

[24] D.J. Scurr, S.J. Eichhorn, Analysis of local deformation in indented Ensis Siliqua mollusk shells using Raman spectroscopy, J. Mater. Res. 21 (12) (2006) 3099-3108. 
[25] M. O’Toole-Howes, R. Ingleby, M. Mertesdorf, J. Dean, W. Li, M.A. Carpenter, E.M. Harper, Deconvolution of the elastic properties of bivalve shell nanocomposites from direct measurement and finite element analysis, J. Mater. Res. 34 (16) (2019) 2869-2880.

[26] S.-E. Choi, T.H. Kim, S.-A. Yi, Y.C. Hwang, W.S. Hwang, S.J. Choe, S.J. Han, H.J. Kim, D.J. Kim, Y. Kang, Capsaicin attenuates palmitate-induced expression of macrophage inflammatory protein 1 and interleukin 8 by increasing palmitate oxidation and reducing c-Jun activation in THP-1 (human acute monocytic leukemia cell) cells, Nutr. Res. 31 (6) (2011) 468-478.

[27] S. Snitker, Y. Fujishima, H. Shen, S. Ott, X. Pi-Sunyer, Y. Furuhata, H. Sato, M Takahashi, Effects of novel capsinoid treatment on fatness and energy metabolism in humans: possible pharmacogenetic implications, Am. J. Clin. Nutr. 89 (1) (2009) 45-50.

[28] L. Chen, Y.-H. Kang, Anti-inflammatory and antioxidant activities of red pepper (Capsicum annuum L.) stalk extracts: comparison of pericarp and placenta extracts, J. Funct. Foods 5 (4) (2013) 1724-1731.

[29] R. Koffi-Nevry, K.C. Kouassi, Z.Y. Nanga, M. Koussémon, G.Y. Loukou, Antibacteria activity of two bell pepper extracts: Capsicum annuum L. and Capsicum frutescens, Int. J. Food Prop. 15 (5) (2012) 961-971.

[30] S. Basith, M. Cui, S. Hong, S. Choi, Harnessing the therapeutic potential of capsaicin and its analogues in pain and other diseases, Molecules 21 (8) (2016) 966.

[31] S. Babbar, J-F. Marier, M.-S. Mouksassi, M. Beliveau, G.F. Vanhove, S. Chanda, K. Bley, Pharmacokinetic analysis of capsaicin after topical administration of a highconcentration capsaicin patch to patients with peripheral neuropathic pain, Ther Drug Monit. 31 (4) (2009) 502-510.

[32] L. Mason, R.A. Moore, S. Derry, J.E. Edwards, H.J. McQuay, Systematic review of topical capsaicin for the treatment of chronic pain, BMJ 328 (7446) (2004) 991

[33] M. Backonja, M.S. Wallace, E.R. Blonsky, B.J. Cutler, P. Malan Jr., R. Rauck, J. Tobias, N.C.S. Group, NGX-4010, a high-concentration capsaicin patch, for the treatment of postherpetic neuralgia: a randomised, double-blind study, Lancet Neurol. 7 (12) (2008) 1106-1112.

[34] M. Kaya, I. Sargin, I. Sabeckis, D. Noreikaite, D. Erdonmez, A.M. Salaberria, J. Labidi, V Baublys, V. Tubelytė, Biological, mechanical, optical and physicochemical properties of natural chitin films obtained from the dorsal pronotum and the wing of cockroach, Carbohydr. Polym. 163 (2017) 162-169.

[35] R.C. Mundargi, M.G. Potroz, S. Park, J.H. Park, H. Shirahama, J.H. Lee, J. Seo, N.J. Cho Lycopodium spores: a naturally manufactured, superrobust biomaterial for drug delivery, Adv. Funct. Mater. 26 (4) (2016) 487-497.

[36] R.C. Mundargi, E.-L. Tan, J. Seo, N.-J. Cho, Encapsulation and controlled release formulations of 5-fluorouracil from natural Lycopodium clavatum spores, J. Ind. Eng. Chem. 36 (2016) 102-108.

[37] M.-H. Schmid-Wendtner, H.C. Korting, The pH of the skin surface and its impact on the barrier function, Skin Pharmacol. Phys. 19 (6) (2006) 296-302.

[38] S.S. D'Souza, P.P. DeLuca, Methods to assess in vitro drug release from injectable polymeric particulate systems, Pharm. Res. 23 (3) (2006) 460-474.

[39] A.I. Bourbon, M.A. Cerqueira, A.A. Vicente, Encapsulation and controlled release of bioactive compounds in lactoferrin-glycomacropeptide nanohydrogels: curcumin and caffeine as model compounds, J. Food Eng. 180 (2016) 110-119.

[40] A.C. Pinheiro, A.I. Bourbon, M.A. Cerqueira, É. Maricato, C. Nunes, M.A. Coimbra, A.A. Vicente, Chitosan/fucoidan multilayer nanocapsules as a vehicle for controlled release of bioactive compounds, Carbohydr. Polym. 115 (2015) 1-9.

[41] S. Dash, P.N. Murthy, L. Nath, P. Chowdhury, Kinetic modeling on drug release from controlled drug delivery systems, Acta Pol. Pharm. 67 (3) (2010) 217-223.

[42] P. Costa, J.M.S. Lobo, Modeling and comparison of dissolution profiles, Eur. J. Pharm Sci. 13 (2) (2001) 123-133.

[43] T. Higuchi, Mechanism of sustained-action medication. Theoretical analysis of rate of release of solid drugs dispersed in solid matrices, J. Pharm. Sci. 52 (12) (1963) 1145-1149.

[44] P. Bersuder, M. Hole, G. Smith, Antioxidants from a heated histidine-glucose model system. I: investigation of the antioxidant role of histidine and isolation of antioxidants by high-performance liquid chromatography, J. Am. Oil Chem. Soc. 75 (2) (1998) 181-187

[45] S.R. Kanatt, M. Rao, S. Chawla, A. Sharma, Active chitosan-polyvinyl alcohol films with natural extracts, Food Hydrocoll. 29 (2) (2012) 290-297.

[46] I. Leceta, P. Guerrero, K. De la Caba, Functional properties of chitosan-based films, Carbohydr. Polym. 93 (1) (2013) 339-346.

[47] H.S. Rathore, T. Senthilvelan, R. Vasantharaja, L.S. Abraham, D. Prakash, U.T. Sivagnanam, S. Gupta, Fabrication and characterization of chitosan film impregnated ciprofloxacin drug: a comparative study, Biocatal. Agric. Biotechnol. 18 (2019) 101078

[48] A.D. Sezer, F. Hatipoglu, E. Cevher, Z. Oğurtan, A.L. Bas, J. Akbuğa, Chitosan film containing fucoidan as a wound dressing for dermal burn healing: preparation and in vitro/in vivo evaluation, AAPS PharmSciTech 8 (2) (2007) E94-E101.

[49] M. Kaya, M. Mujtaba, H. Ehrlich, A.M. Salaberria, T. Baran, C.T. Amemiya, R. Galli, L. Akyuz, I. Sargin, J. Labidi, On chemistry of $\gamma$-chitin, Carbohydr. Polym. 176 (2017) 177-186.

[50] M.K. Jang, B.G. Kong, Y.I. Jeong, C.H. Lee, J.W. Nah, Physicochemical characterization of $\alpha$-chitin, $\beta$-chitin, and $\gamma$-chitin separated from natural resources, J. Polym. Sci. Pol. Chem. 42 (14) (2004) 3423-3432.

[51] I. Corazzari, R. Nisticò, F. Turci, M.G. Faga, F. Franzoso, S. Tabasso, G. Magnacca, Advanced physico-chemical characterization of chitosan by means of TGA coupled on-line with FTIR and GCMS: thermal degradation and water adsorption capacity, Polym. Degrad. Stab. 112 (2015) 1-9.

[52] C.H. Chen, F.Y. Wang, Z.P. Ou, Deacetylation of $\beta$-chitin. I. Influence of the deacetylation conditions, J. Appl. Polym. 93 (5) (2004) 2416-2422.

[53] M. Kaya, I. Sargin, V. Aylanc, M.N. Tomruk, S. Gevrek, I. Karatoprak, N. Colak, Y.G. Sak, E. Bulut, Comparison of bovine serum albumin adsorption capacities of $\alpha$-chitin isolated from an insect and $\beta$-chitin from cuttlebone, J. Ind. Eng. Chem. 38 (2016) 146-156.

[54] A.T. Paulino, J.I. Simionato, J.C. Garcia, J. Nozaki, Characterization of chitosan and chitin produced from silkworm crysalides, Carbohydr. Polym. 64 (1) (2006) 98-103.

[55] Y. Ma, X. Cao, X. Feng, Y. Ma, H. Zou, Fabrication of super-hydrophobic film from PMMA with intrinsic water contact angle below 90, Polymer 48 (26) (2007) 7455-7460.

[56] Z.-D. Qi, T. Saito, Y. Fan, A. Isogai, Multifunctional coating films by layer-by-layer desposition of cellulose and chitin nanofibrils, Biomacromolecules 13 (2) (2012) 553-558.

[57] J.-B. Zeng, Y.-S. He, S.-L. Li, Y.-Z. Wang, Chitin whiskers: an overview, Biomacromoleculess 13 (1) (2012) 1-11.

[58] G. He, Z. Wang, H. Zheng, Y. Yin, X. Xiong, R. Lin, Preparation, characterization and properties of aminoethyl chitin hydrogels, Carbohydr. Polym. 90 (4) (2012) 1614-1619.

[59] M. Rinaudo, Chitin and chitosan: properties and applications, Prog. Polym. Sci. 31 (7) (2006) 603-632.

[60] G. Singhvi, M. Singh, In-vitro drug release characterization models, Int. J. Pharm. Stud. Res. 2 (1) (2011) 77-84.

[61] L. Serra, J. Doménech, N.A. Peppas, Drug transport mechanisms and release kinetics from molecularly designed poly (acrylic acid-g-ethylene glycol) hydrogels, Biomaterials 27 (31) (2006) 5440-5451.

[62] M. Lavorgna, E. Orlo, R. Nugnes, C. Piscitelli, C. Russo, M. Isidori, Capsaicin in hot chili peppers: in vitro evaluation of its antiradical, antiproliferative and apoptotic activities, Plant Food Hum. Nutr. 74 (2) (2019) 164-170.

[63] T. Amna, F.N. Gharsan, K. Shang, M.S. Hassan, M.-S. Khil, I. Hwang, Electrospun twin fibers encumbered with intrinsic antioxidant activity as prospective bandage, Macromol. Res. 27 (7) (2019) 663-669.

[64] L. Akyuz, M. Kaya, M. Mujtaba, S. Ilk, I. Sargin, A.M. Salaberria, J. Labidi, Y.S. Cakmak, C. Islek, Supplementing capsaicin with chitosan-based films enhanced the antiquorum sensing, antimicrobial, antioxidant, transparency, elasticity and hydrophobicity, Int. J. Biol. Macromol. 115 (2018) 438-446. 